\title{
Demand Potential On Canal Utilization As Alternative Urbantransportation Medium In Makassar City
}

\author{
Amiruddin Akbar Fisu, Ibnu Syabri
}

\begin{abstract}
Water transportation is the transportation of people and goods using water modes as a means of connecting one location to another. There are three canals in the center of Makassar City with a total length of $15.11 \mathrm{~km}$. These canals function as an urban drainage and also as a main base for flood control. This canal has become one of the potentials that can be used to unravel road-based movements while at the same time solving the congestion problems that occur in Makassar City by utilizing it as an urban transportation medium both as a travel for daily needs (formal) and recreational activities (non-formal). This research was conducted to see how the demand preferences of canal-based transportation modes, variables that affect the willingness to use channels as a transportation medium, and the extent to which the role of channels becomes an alternative transportation medium. This study uses a descriptive quantitative method approach to achieve these objectives using the method of crosstab analysis, multinomial logistic regression and approaches with stated preference methods. Based on the results of the analysis, there are four variables that significantly affect respondents' willingness to use canal / waterway based transportation services, namely income per month, travel time, reasons for choosing modes, and tariff tolerance. In the stated preference analysis, the results show that the operation of the waterway transportation will cause the shift of road-based mode users to travel, where the increase is $31.10 \%$ for scenario 1 and $37.26 \%$ for scenario 2 .
\end{abstract}

Index Terms: Canal Transportation, Waterway, Stated Preference, Urban Transportation, Makassar.

\section{INTRODUCTION}

CONGESTION in the city of Makassar is inseparable from the uncontrolled growth rate of vehicles, in the last five years. Based on 2019 data the number of vehicles operating in Makassar reached 2,1 million units, this figure is growing at around 7 percent per year and the imbalance with the development of existing transportation infrastructure has aggravated the traffic conditions in Makassar City. One of the potentials that can be utilized to solve congestion problems that occur in Makassar City is to use the canal as a medium of urban transportation both as a trip for daily needs (formal) and recreational activities (non-formal). According to Liao [1], canal transportation has the potential to be developed as water transportation on land by utilizing canals to reduce congestion in urban areas. This was also supported by Chen et al, [2] where urban canals can also be an alternative for transportation of goods when the streets are crowded with vehicles that serve other needs. Even the canal/waterway transportation system is particularly cost effective in the transportation although it is still often underestimated as an adequate means of transportation for urban activities.

In many countries, canal transportation has been developed in such a way as to support the existing transportation system. The Panama and the Zues Canal are may be a significant example of where modifications to the mainland can be made to enable the interconnectivity of many ports throughout the world to run more efficiently through waterways [3], in which mainly for logistics and container transportation [4]. In a modern urban scale, the use of canal systems can be found, among others, in New York City as a transportation medium for commercial and tourism [5]. In addition, technology in the design of urban waterway-based transportation facilities is also

- Author : Amiruddin Akbar Fisu, Assistant Professor, Engineering Departement at Universitas Andi Djemma, Indonesia, E-mail: amiruddinakbarfisu07@gmail.com

- Co-Author Ibnu Syabri, Associate Professor, Regional and City Planning Departement at Institut Teknologi Bandung, Indonesia, Email: syabri@pl.itb.ac.id

- Correnspondent : amiruddinakbarfisu07@gmail.com increasingly developing such as the prototyping of water transportation using the autopilot system, Reboat, in Macau [6]. However, in the application of this waterway-based transportation system, it is necessary to pay attention to different technical aspects that are not owned by conventional transportation systems by road [7]. In other cases, with the increasingly busy transportation medium on land and (soon) in waters, it is necessary to anticipate the impacts that will emerge later. For example, in a big city like Beijing, the increasingly crowded water transportation activities have contributed to more air pollution due to carbon emissions from ship exhaust [8]. Makassar City has three main canals with a total length reaching $15.11 \mathrm{~km}$, consisting of the $7.83 \mathrm{~km}$ Jongayya Canal which empties into Makassar Strait, Panampu Canal $4.92 \mathrm{~km}$ which empties into the Paotere fish port area north of the city, and The $2.36 \mathrm{~km}$ Sinrijala Canal which empties into the Tallo River, east of Makassar. The Jongaya and Panampu canals are crossed the Sinrijala canal. Since 1990 , these canals have been functioning as urban drainage and also as a main base for flood control. Canal is one of the potentials that can be utilized to solve congestion problems that occur in Makassar City, namely using canals as a mode of urban transportation, both as a trip for daily needs (formal) and recreational activities (non-formal). In addition, the use of canals as a means of transportation can also support the activities of the fishing industry in the Port of Paotere [9]. Canal transportation is one solution to reduce congestion problems that occur in Makassar.

There have been several previous studies related to the use of canals as a transportation medium in Makassar City, but there have not been many studies related to channel demand from objects or potential users of alternative channel-based transportation. The purpose of this study is to find out how much the potential demand of waterway-based transportation modes in the Panampu and Jongaya canals, the factors that influence the user "wants" or "reluctant" to use the canal as an alternative transportation medium. To identify user preferences related to canal planning as a transportation medium, and identify the extent to which the role of the Jongaya and Panampu canals can be an alternative transportation medium, 
either as a competitor or complement, to road-based transportation in Makassar City.

\section{RESEARCH METHOD}

\subsection{Analysis technique Crosstab analysis}

Crosstab analysis or commonly referred to as cross tabulation analysis is a method of analyzing data categories using nominal, ordinal, interval and combination data. The cross tabulation procedure is used to count the number of cases that have a combination of different values of two variables and calculate the statistical prices along with the test [10] . Cross Tabulation Analysis can be used in solving data analysis problems. The benefits that can be obtained from cross tabulation analysis, especially in transportation related studies, are:

1. Help complete transportation studies related in determining the relationship between variables or factors obtained from qualitative data, after passing statistical tests.

2. Determine the degree of association (strong or weak relationship)

3. Can determine the dependent variable (dependent) and independent variables (independent) of the two variables analyzed.

\section{Multinominal logistic regression}

Multinomial logistic regression or also called politomus logit model is a regression model used to resolve regression cases with the dependent variable in the form of multinomials qualitative data (more than two categories) with one or more independent variables. The method is used to explain how to estimate parameters in multinomial logistic regression using the maximum likelihood method and to illustrate examples of multinomial logistic regression models. The equation of the multinomial logistic regression model can be written in equation (1) as follows:

$g(x)=\beta_{0}+\beta_{1} x_{1}+\beta_{2} x_{2}+\cdots+\beta_{k} x_{k}$

where $g_{j}(x)$ is the dependent variable in the form of a politomus category variable with a nominal measurement scale, $x_{p}$ is the dependent variable in the form of a politomus category variable with a nominal measurement scale, and $\beta_{\mathrm{p}}$ is a parameter The method used to estimate the parameters of the multinomial logistic regression model at this writing is the maximum likelihood method. The likelihood equation in multinomial logistic regression is a nonlinear equation in the parameters of the regression coefficient, $\beta_{j \mathrm{p}}, \beta_{\mathrm{jp}}$ so to solve the equation until the estimated value of the parameter is used Newton Raphson algorithm. Then after the parameter estimation is obtained, the parameter real level test is performed using the likelihood ratio test and the Wald test.

Stated Preference

As quoted in Ortuzar [11] states that to display the appeal of an alternative, use the concept of utility. Utility is defined as a special measure for someone in determining the best alternative choice. Utility is a function of alternative attributes of the characteristics of decision makers. So the utility function is to exchange the attractiveness of each choice (hypothetical scenario) given to the respondent. This function reflects the effect of the choice of respondents on all attributes included in the stated preference. Utilities cannot be measured directly, therefore some attributes that affect individual utilities are treated in a random form, meaning that the choice being modeled only gives probability to the alternative chosen, and not the choice itself. Utilities can be measured from the total attributes such as travel speed, cost, time, security, comfort, service and others.

The form of the utility function is difficult to model, but for simplicity it is assumed to be linear in shape as shown in equation (2) below:

$$
U_{i}=a_{0}+a_{1} x_{1}+a_{2} x_{2}+a_{3} x_{3}+\cdots
$$

where :

$\mathrm{U}_{\mathrm{i}} \quad=$ choosen utilities

$\mathrm{a}_{0 \ldots \ldots \ldots \ldots \ldots \ldots . . . . . . . . .} \mathrm{a}_{\mathrm{n}}=$ model parameter.

$\mathrm{x}_{1 \ldots \ldots \ldots \ldots \ldots . . . . . . . . .} \mathrm{x}_{\mathrm{n}}=$ attribute value

In this study, researchers compared canal transportation alternatives with city public transportation facilities known as angkot. Angkot is one of the road-based public transport that functions as a paratransit with a capacity of 8-10 people.

\subsection{Approach}

The approach taken in this study is a quantitative descriptive approach. Cresswell [12] defines descriptive research as "Qualitative research is descriptive in that the researcher is interested in the process, meaning, and understanding gained through words or pictures." Research in this definition is that researchers must be interested in the process, meaning and understanding which are then described in the form of writing or illustration. According to Punch [13], quantitative research methods are empirical research in which data is in the form of something that is calculated / numbered. Quantitative research pays attention to the collection and analysis of data in numerical forms. This approach is applied to the community as a prospective user of river transportation to find out what factors can influence the community's willingness to use water transportation which also reviews aspects of service facilities to find out what service facilities are prioritized by prospective river transportation users.

\subsection{Data Collection}

To complement this quantitative method, a sampling technique in the form of the Purposive Random Sampling method is used, according to Hadi [14], this method is a sampling technique by taking into account the considerations made by the researcher, where the sampling technique will be applied in the study area of research with randomly drawing and sampling the population covered in kelurahan units around the canal.

The error value in the desired sample is below 5\% (a $=0.05$ ), in other words the level of confidence of the data is 95\%. Based on the Lemeshow formula for Population unknown number of samples can be calculated through the number of populations and error values. According to calculations, the minimum number of samples with $\alpha=0.05$ is 384 samples. Based on the determination of the number of samples from the Lameshow formula, this study uses 400 samples. It can be said the number of samples represents $0.14 \%$ of the population in the area around the canal, or about $0.65 \%$ of the total number of households around the canal. After determining the number of samples, it is necessary to 
determine the method of sampling. In general, the population is divided into three categories, namely:

1. a community that lives around a canal (a residential area that enters a delineation radius of 400 meters to the left or right of the canal),

2. people who are active around the canals, be it the campus, schools, offices, markets, etc. (educational facilities, offices, trade, etc. that enter the delineation radius 400 meters to the left or right of the canal),

3. people who live around the canal and also do activities around the canal.

The delineation area of 400 meters left and right of the canal covering an area of approximately $10,960 \mathrm{~km} 2$ was then divided into three zones, where, in each zone a total of 133134 respondents were taken based on their land use, namely settlements, trade, education, and other activities. In addition to the settlement area around the canal, the distribution of questionnaires also considers areas or centers of activity with a fairly high number of attractions such as markets, campuses, hospitals, and several other places that are considered to have high attractions.

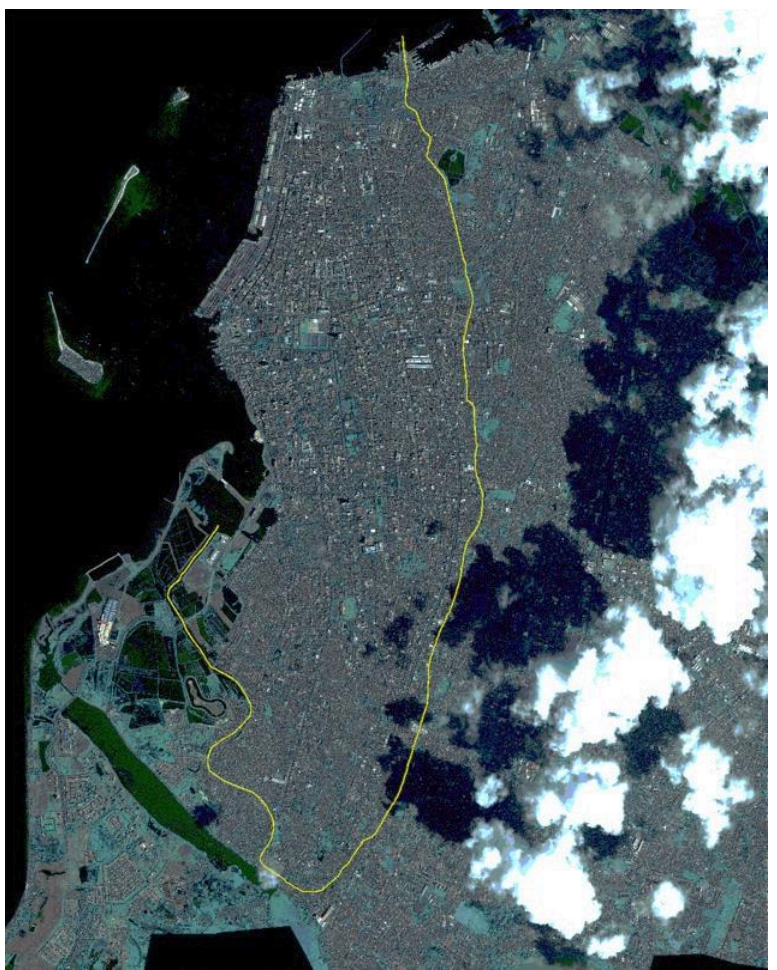

Fig. 1. The city of Makassar traversed by canals Jongaya and Panampu

\section{Result and Discussion}

As explained in the basic part of the theory, the analytical method used is a crosstab analysis to see the relationship of each variable. After that multinomial logistic regression tools are used, to explain how to estimate parameters in multinomial logistic regression by using the maximum likelihood method and explain an illustrative example of a multinomial logistic regression model. After that the stated preference method is used by using 16 scenarios which can be seen in the table below:
TABLE 1 STATED PREFERENCE SCENARIO

\begin{tabular}{|c|c|c|c|c|}
\hline Scenario & Tariff & $\begin{array}{c}\text { waiting } \\
\text { time }\end{array}$ & $\begin{array}{c}\text { mode's } \\
\text { capacity }\end{array}$ & speed \\
\hline 1 & $<$ RP. $2.000-$ Rp. 4.000 & 15 minutes & 15 & 20 \\
\hline 2 & $<$ RP. $2.000-$ Rp. 4.000 & 15 minutes & 15 & 30 \\
\hline 3 & $<$ RP. $2.000-$ Rp. 4.000 & 15 minutes & 20 & 20 \\
\hline 4 & $<$ RP. $2.000-$ Rp. 4.000 & 15 minutes & 20 & 30 \\
\hline 5 & $<$ RP. $2.000-$ Rp. 4.000 & 25 minutes & 15 & 20 \\
\hline 6 & $<$ RP. $2.000-$ Rp. 4.000 & 25 minutes & 15 & 30 \\
\hline 7 & $<$ RP. $2.000-$ Rp. 4.000 & 25 minutes & 20 & 20 \\
\hline 8 & $<$ RP. 2.000 - Rp. 4.000 & 25 minutes & 20 & 30 \\
\hline 9 & $>$ Rp. 4.000 - Rp. 6.000 & 15 minutes & 15 & 20 \\
\hline 10 & > Rp. 4.000 - Rp. 6.000 & 15 minutes & 15 & 30 \\
\hline 11 & > Rp. 4.000 - Rp. 6.000 & 15 minutes & 20 & 20 \\
\hline 12 & $>$ Rp. 4.000 - Rp. 6.000 & 15 minutes & 20 & 30 \\
\hline 13 & > Rp. 4.000 - Rp. 6.000 & 25 minutes & 15 & 20 \\
\hline 14 & $>$ Rp. 4.000 - Rp. 6.000 & 25 minutes & 15 & 30 \\
\hline 15 & $>$ Rp. 4.000 - Rp. 6.000 & 25 minutes & 20 & 20 \\
\hline 16 & $>$ Rp. 4.000 - Rp. 6.000 & 25 minutes & 20 & 30 \\
\hline
\end{tabular}

From the data obtained through the primary survey with the questionnaire is still in the form of ordinal data, where individual responses are still in the form of choices to the rating points presented on the semantic scale, namely: $1=$ definitely utilizing the mode of transportation of channels, $2=$ balanced/combining canal modes and road-based modes , $3=$ Do not use canal transportation mode (continue to use road based mode as before). In the next analysis, quantification and transformation of the data obtained is carried out. The semantic scale is then transformed into a numerical scale (a value that represents an individual's response to a choice statement) using a linear transformation of the binomial logit model on the probability for each rating point. The numerical scale value is the dependent variable in the regression analysis and the independent variable is the difference in attribute values between the canal mode and the road mode. The process of transformation from a semantic scale to a numerical scale is as follows: The value of the choice of probability scale represented by point ratings 1,2 , and 3 is the standard scale value of $0.9 ; 0.5$; and 0.3 . By using the linear transformation of the binary logit model a numerical scale value for each option's probability is obtained. For point rating 1 with a probability value of 0.9 , the numerical scale value is: In $[0.9 /(1-0.9)]=2.1972$. Point rating 2 with a probability value of 0.5 , the numerical scale value is: In $[0.5 /(1-0.5)]=$ 0.0 . Point rating 3 with a probability value of 0.1 , the numerical scale value is: In $[0.1 /(1-0.1)]=-2,1972$. Crosstab analysis is then performed to see how the relationship or association that occurs between respondents' willingness to use canal mode with various characteristics of respondents, both socioeconomic characteristics, movements, and responses to waterway-based transportation. Hypothesis for this case: Ho: There is no relationship between independent variables and respondents' willingness to use canal/waterway based modes. $\mathrm{Hi}$ : There is a relationship between independent variables and respondents' willingness to use canal /waterway based modes. Based on comparisons of chi-Square counts with chiSquare tables: If chi-Square counts < chi-Square tables then $\mathrm{Ho}$ is accepted, but if chi-Square counts > chi-Square tables then $\mathrm{Ho}$ is rejected. Based on the results of the analysis shown in table 2, it is known that there are six variables whose Ho is accepted, or in this case it can be concluded that it does not have a significant relationship to the responses of respondents in the operation of canal/waterway based transportation services. These variables include age, sex, occupation, number of modal shifts, and waiting time tolerance. Whereas the other 10 variables $\mathrm{Ho}$ are rejected or have a relationship to the responses of the respondents to the 
planned operation of canal/waterway based transportation services.

Table 2

Chi Square Test Crosstab Analysis

\begin{tabular}{|c|c|c|c|c|c|c|}
\hline \multirow{2}{*}{ Variable } & \multirow{2}{*}{ Pearson Chi Square } & \multicolumn{3}{|c|}{ chi square test 1} & \multicolumn{2}{|c|}{ chi square test 2} \\
\hline & & chi square calculation & df & chi square table conclution & Asymp. Sig & $\alpha \quad$ conclusion \\
\hline $\mathrm{x}_{1}$ & AGE & 5.79 & 2 & 5.991 H0.Accepted & 0.038 & 0.05 H0.Accepted \\
\hline$x_{2}$ & SEX & 4.645 & 4 & 9.488 H0.Accepted & 0.011 & 0.05 H0.Accepted \\
\hline$x_{3}$ & LATEST EDUCATION & 11.43 & 10 & 18.307 H0.Accepted & 0.281 & 0.05 H0.Accepted \\
\hline$x_{4}$ & OCCUPATION & 5.043 & 8 & 15.507 H0.Accepted & 0.663 & 0.05 H0.Accepted \\
\hline $\mathrm{x} 5$ & INCOME & 42.267 & 8 & 15.507 H0.Rejected & 0.00 & 0.05 H0.Rejected \\
\hline$x_{6}$ & DISTANCE & 5.121 & 2 & 5.991 H0.Accepted & 0.076 & 0.05 H0.Accepted \\
\hline$x 7$ & TRAVEL TIME & 10.83 & 2 & 5.991 Ho.Rejected & 0.008 & 0.05 H0.Rejected \\
\hline $\mathrm{x}_{8}$ & MODE USED & 3.525 & 4 & 9.488 H0.Accepted & 0.519 & 0.05 H0.Accepted \\
\hline$x 9$ & REASON TO CHOOSE MODE & 20.237 & 10 & 18.307 HO.Rejected & 0.009 & 0.05 H0.Rejected \\
\hline $\mathrm{x} 10 \mathrm{~A}$ & OWNERSHIP. CAR & 2.378 & 2 & 5.991 H0.Accepted & 0.287 & 0.05 H0.Accepted \\
\hline $\mathrm{X} 10 \mathrm{~B}$ & OWNERSHIP. MOTORBIKE & 3.78 & 2 & 5.991 H0.Accepted & 0.13 & 0.05 H0.Accepted \\
\hline $\mathrm{x} 11$ & MODE MOVEMENT & 2.897 & 2 & 5.991 H0.Accepted & 0.815 & 0.05 H0.Accepted \\
\hline $\mathrm{x} 12$ & $\begin{array}{l}\text { DAIIY TRANSPORTATION } \\
\text { COST }\end{array}$ & 13.406 & 10 & 18.307 H0.Accepted & 0.245 & 0.05 H0.Accepted \\
\hline $\mathrm{x} 13$ & TARIFF TOLERANCE & 278.211 & 2 & 5.991 Ho.Rejected & 0.00 & 0.05 H0.Rejected \\
\hline $\mathrm{x} 14$ & WAITING TIME TOLERANCE & 2.927 & 2 & 5.991 H0.Accepted & 0.236 & 0.05 H0.Accepted \\
\hline $\mathrm{x} 15$ & $\begin{array}{l}\text { TIME TRAVEL } \\
\text { TOLERANCE }\end{array}$ & 0.314 & 2 & 5.991 H0.Accepted & 0.81 & 0.05 H0.Accepted \\
\hline $\mathrm{x} 16$ & $\begin{array}{l}\text { MODE CAPACITY } \\
\text { TOLERANCE }\end{array}$ & 2.464 & 2 & 5.991 H0.Accepted & 0.21 & 0.05 H0.Accepted \\
\hline
\end{tabular}

In the analysis of factors that affect the willingness of respondents to use waterway-based modes with multinominal logistic regression, the hypothesis for this case is:

Ho: None of the independent variables that are statistically significantly affect the dependent variable in this case is the response of respondents to the operation of transport services based canal/ waterway.

$\mathrm{Hi}$ : At least there is one independent variable is statistically significantly affect the dependent variable in this case is the response of respondents to the operation of transport services based canal/ waterway.

The critical area/reject $\mathrm{Ho}$ is if the prob value of Chi Square $(\mathrm{db}=\mathrm{k}-1)$ is smaller than the alpha value of $5 \%$ or the calculated chi square is greater than the chi square table. The value of degree of freedom for this test is 74 . Based on the results of the analysis, it turns out that the resulting chi square probability value is 0,000 or smaller than alpha of $5 \%$. Thus Ho is rejected and states that there is at least one variable that significantly influences the dependent variable or the response or willingness of the respondents to the planning of this canal/waterway-based public transport operation. From the partial test results, it appears that there are 4 variables that statistically significantly affect the dependent variable $(Y)$ or the response/willingness of respondents to the operation of canal/waterway based transportation services. These variables include travel time (X7), tariff tolerance (X13), monthly income (X5), and reasons for choosing mode (X9). The results of a partial test for all independent variables $(X)$ to the dependent variable $(\mathrm{Y})$ can be seen in Table 3.
Table 3

Chi Square Test Multinomial Logistic Regression

\begin{tabular}{|c|c|c|c|c|c|c|c|c|}
\hline \multirow{2}{*}{ Variable } & \multirow{2}{*}{ Pearson Chi Square } & \multicolumn{4}{|c|}{ chi square test 1} & \multicolumn{3}{|c|}{ chi square test 2} \\
\hline & & chis square calculation & & chi square table & conclution & Asymp. Sig & & conclution \\
\hline $\mathrm{XI}$ & AGE & 119.404 & 98 & 122.108 & H0 Acceppled & 0.07 & 0.05 & \\
\hline $\mathrm{x}_{2}$ & SEX & 3.824 & 4 & 9.488 & H0 Accepted & 0.43 & 0.05 & H0 Accepted \\
\hline$x_{3}$ & LATEST EDUCATION & 26.271 & 10 & 18.307 & HO Rejected & 0.003 & & HO Rejected \\
\hline $\mathrm{x} 4$ & OCCUPATION & 15.448 & 8 & 15.507 & H0 Accepted & 0.051 & 0.05 & H0 Accepted \\
\hline Xs & INCOME & 172.361 & 8 & 15.507 & HО Rejected & 0.00 & 0.05 & HO Rejected \\
\hline $\mathrm{x} 6$ & DISTANCE & 60.433 & 52 & 69.832 & H0 Accepted & 0.197 & 0.05 & H0Accepted \\
\hline $\mathrm{x} 7$ & TRAVEL TIME & 49.164 & 26 & 38.885 & HO Rejected & 0.004 & 0.05 & HO Rejected \\
\hline $\mathrm{X} 8$ & MODE USED & 12.857 & 4 & 9.488 & HО Rejected & 0.012 & 0.05 & HO Rejected \\
\hline $\mathrm{x} 9$ & REASON TO CHOOSE MODE & 28.792 & 10 & 18.307 & нО Rejected & 0.001 & 0.05 & но Rejected \\
\hline $\mathrm{X} 10 \mathrm{~A}$ & OWNERSHIP OF CAR & 17.865 & 4 & 9.488 & HO Rejected & 0.001 & 0.05 & Hо Rejected \\
\hline $\mathrm{x} 10 \mathrm{~B}$ & OWNERSHIP OF I & 37.251 & 10 & 18.307 & HO Rejected & 0.00 & 0.05 & HO Rejected \\
\hline $\mathrm{x} 11$ & MODE MOVEMENT & 7.421 & 8 & 15.507 & HO Accepted & 0.491 & 0.05 & H0 Accepted \\
\hline $\mathrm{X} 12$ & $\begin{array}{l}\text { DAILY TRANSPORTATION } \\
\text { COST }\end{array}$ & 29.458 & 10 & 18.307 & но Rejected & 0.001 & 0.05 & HO Rejected \\
\hline $\mathrm{x} 13$ & TARIFF TOLERANCE & 534.575 & 36 & 50.998 & HO Rejected & 0.00 & 0.05 & HO Rejected \\
\hline $\mathrm{X} 14$ & $\begin{array}{l}\text { WAITING TIME } \\
\text { TOLERANCE }\end{array}$ & 36.358 & 24 & 36.415 & H0 Accepted & 0.051 & 0.05 & HO Accepted \\
\hline $\mathrm{X} 15$ & $\begin{array}{l}\text { TRAVEL TIME } \\
\text { TOLERANCE }\end{array}$ & 67.746 & 32 & 46.194 & HO Rejected & 0.00 & 0.05 & HO Rejected \\
\hline $\mathrm{X} 16$ & $\begin{array}{l}\text { MODE CAPACTYY } \\
\text { TOLERANCE }\end{array}$ & 50.176 & 20 & 31.41 & HO Rejected & 0.00 & 0.05 & HО Rejected \\
\hline
\end{tabular}

To see the goodness of fit, it can be seen in table 4, where the Nageikerke value is 0.859 , which indicates that the diversity of data from the independent variables in the study is able to explain the diversity of the dependent variable by $85.9 \%$, while the rest is explained by other independent variables that are outside this research model.

\section{Table 4}

PSEUDO R-SQUARE

\begin{tabular}{ll}
\hline Cox and Snell & .745 \\
Nageikerke & .859 \\
McFadden & .669 \\
\hline
\end{tabular}

Based on this analysis, and by removing or ignoring independent variables that do not significantly affect the dependent variable, the two models produced can be seen in model (3) and model (4):

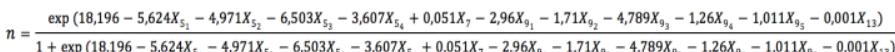

$$
\begin{array}{ll}
\mathrm{n}_{\mathrm{N}} & =\text { potentially might use waterway mode } \\
\mathrm{X}_{5 \beta} & =\text { income category } \beta \\
\mathrm{X}_{7} & =\text { traveling time } \\
\mathrm{X}_{9 \beta} & =\text { reasons for choosing the mode category } \beta \\
\mathrm{X}_{13} & =\text { tariff tolerance }
\end{array}
$$

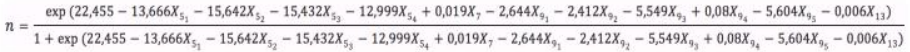

$\mathrm{n} \quad=$ potentially might not use waterway mode

$\mathrm{X}_{5 \beta} \quad=$ income category $\beta$

$\mathrm{X}_{7} \quad=$ traveling time

$\mathrm{X}_{9 \beta} \quad=$ reasons for choosing the mode category $\beta$

$\mathrm{X}_{13}=$ tariff tolerance

In the analysis of the Model Selection between Canal/Waterway Based Transportation Modes and Road Based Transportation Modes (angkot) using stated preference analysis, data compilation using regression analysis produce estimated parameters that will be used in the model. The results of the regression analysis with SPSS software can be concluded as follows: 
1. Regression results show that the significance level of regression is good enough by showing the statistical value where the R-square is 0.534 (above $50 \%$ ).

2. The resulting model formulation is a multi-linear utility function in which the variables are service attributes related to canal/waterway mode and road/angkot mode which are considered to influence mode selection.

3. In general, the coefficient value generated by each variable in the mode's selection model is as expected to be negative (-). This means that if the tariff, waiting time, mode's speed or canal mode's capacity are lower, many potential users or users of transport services will use $\mathrm{road} / \mathrm{angkot}$-based transportation or vice versa.

Based on the explanation above, it can be concluded that, model (5) which represents the mode selection obtained from the results of the regression analysis.

$P_{\mathrm{K}}=\frac{\exp \left(4,598-0,001 X_{1}-0,155 X_{2}-0,108 X_{3}-0,007 X_{0}\right)}{1+\exp \left(4,598-0,001 X_{1}-0,155 X_{2}-0,108 X_{3}-0,007 X_{1}\right)}$

(5)

and for the probability of selecting road/angkot-based transport mode can be seen in the model (6)

$P_{f}=\frac{1}{1+\exp \left(4,598-0,001 X_{1}-0,155 X_{2}-0,108 X_{3}-0,007 X_{1}\right)}$

(6)

ket:

$\mathrm{P}_{\mathrm{K}}=$ Probability of choosing canal /waterway-based transport modes

$P_{J}=$ Election probability-based transport modes road/public transportation

$X_{1}=\Delta$ tarriff

$\mathrm{X}_{2}=\Delta$ waiting time

$\mathrm{X}_{3}=\Delta$ mode capacity

$\mathrm{X}_{4}=\Delta$ mode speed

Based on the results of the utility function above, then the relationship between the probability of mode selection and the difference between the utility mode of the canal/waterway and the road mode can be obtained. Calculation of the relationship between the utility and the probability of choosing the mode can be seen in the graph/figure 1

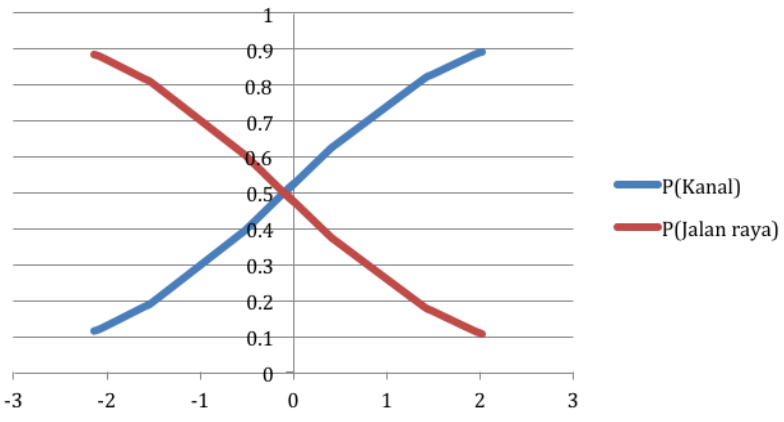

Fig. 2. Graph of canal and road mode selection probability

Can be seen from the table and graph above, that the greater the difference in utility between the canal/waterway mode and the road mode, the higher the chance for someone to choose the canal/waterway mode and vice versa. The graph shows that the steepness of the line of functions between negative and positive values is relatively the same, both positive and negative, so that the change in utility in both directions gives a change in the probability of mode selection tends to be the same. In the sensitivity analysis it can be seen the probability value of waterway-based mode selection if the attribute value changes gradually. The assumption used is that changes in the value of an attribute will not affect other attributes, so the reverse effect is not taken into account.

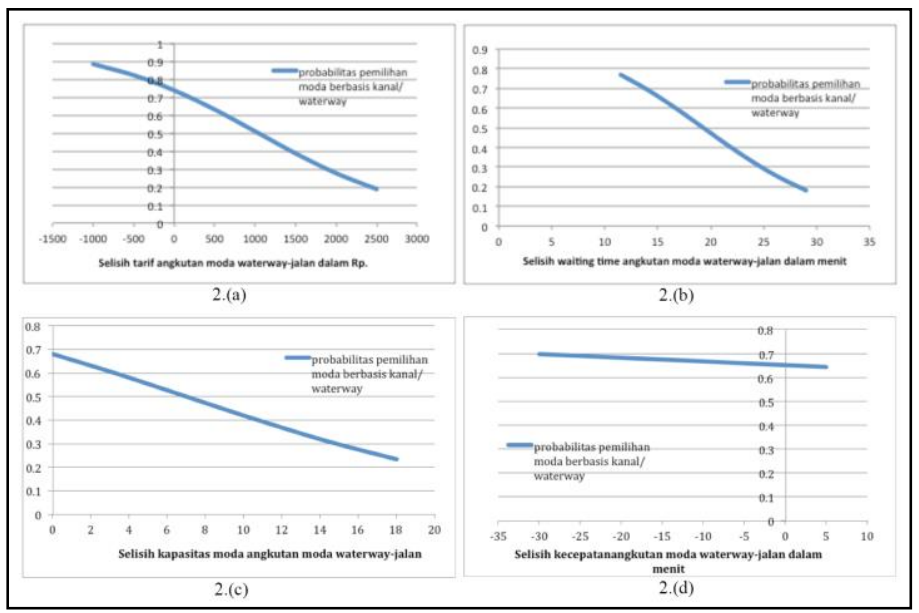

Fig. 3. Graphic sensitivity of each attribute

(a): Sensitivity graphs for tariff attributes, (b): Sensitivity graphs for waiting time attributes, (c): Sensitivity graphs for mode's capacity attributes, (d): Sensitivity graphs for mode's speed attributes

The mode selection model is based on the results of the model studies that have been analyzed above. The model is implemented in the study area, namely the Panampu and Jongaya Canal hinterlands. In the first scenario the value of the attribute or the difference in tariff (X1) of the modes of roadways is $R p .2000$, the waiting time attribute (X2) has a difference of 14 minutes, the mode's capacity attribute has a difference of 10 people, and the speed attribute (X4) has difference in value of $-20 \mathrm{~km} /$ hour. Thus, the planned operation of the canal/waterway mode for scenario 1 is at a rate of Rp. 6000 , waiting time of 15 minutes, mode's capacity of 20 people and speed of $20 \mathrm{~km} / \mathrm{hour}$. In the second scenario the value of the attribute or the difference in tariff (X1) of the modes of roadways is Rp. 1500, the waiting time attribute (X2) has a difference of 19 minutes, the mode's capacity attribute has a difference of 10 people, and the speed attribute (X4) has difference in value of $-20 \mathrm{~km} /$ hour. Therefore, the planned operation of the canal/waterway mode for the second scenario is Rp. 5,500 for tariff, waiting time of 20 minutes, mode's capacity of 20 people and speed of $20 \mathrm{~km} / \mathrm{hour}$. The assumption for utilities in the road mode using angkot (public micro bus) does not change, namely with a flat rate of $\mathrm{Rp}$. 4,000 , the average waiting time is 1 minute, the capacity is 10 people, and the speed is $40 \mathrm{~km} /$ hour. A graph of the increase in canal/waterway-based transportation service users by operating a canal/waterway-based water transportation system can be seen in Figure 4. 


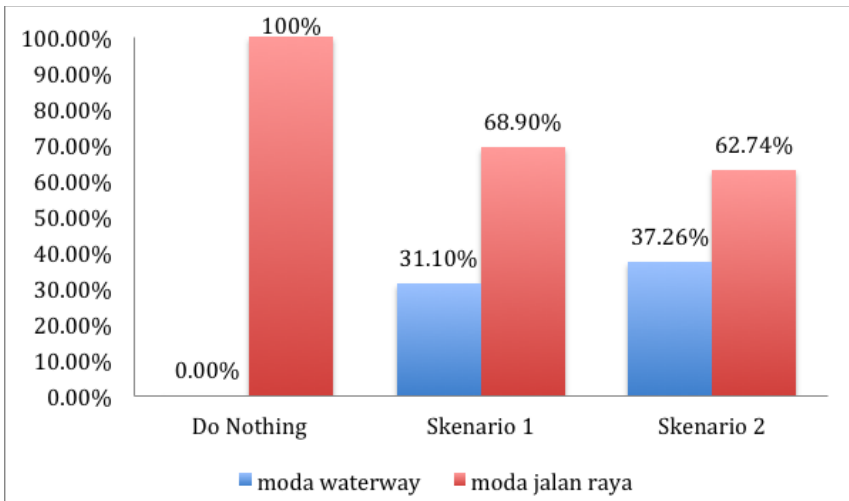

Fig. 4. Graph of potential users of waterway mode and road mode transport users based on the planned scenario

From the picture above shows that the operation of alternative water transportation based on canals/waterway will cause the shift of road-based mode users to travel for daily activities, the increase is $31.10 \%$ for scenario 1 and $37.26 \%$ for scenario 2 While road/angkot-based mode users will decrease to $68.90 \%$ in the first scenario and $62.74 \%$ in the second scenario

\section{CONCLUSION}

Based on the study findings, the use of canals as an alternative transportation medium is possible to look at the potential demand that exists, and can consider cheap and affordable tariff policies by the public government or the operator needs to consider operational policies to speed up travel time. The number of stopping places needs to be multiplied and placed in locations that are easily accessible, besides that feeders need to be provided to be able to access canals or stop areas easily and quickly. The government or the operator needs to determine operational policies by sharing the characteristics of the route, i.e. for short routes, medium routes and long routes. This is related to travel time so that it can streamline the movement of prospective users.

\section{REFERENCES}

[1] P. Liao, "Analytical model to estimate lock capacity of a waterway lock," Transp. Res. Board, 92nd Annu. Meet., pp. 1-14, 2013.

[2] L. Chen, Y. Huang, H. Zheng, H. Hopman, and R. Negenborn, "Cooperative Multi-Vessel Systems in Urban Waterway Networks," IEEE Trans. Intell. Transp. Syst., pp. 1-14, 2019.

[3] J. Zheng, W. Zhang, J. Qi, and S. Wang, "Canal effects on a liner hub location problem," Transp. Res. Part E Logist. Transp. Rev., vol. 130, pp. 230-247, 2019.

[4] R. Ungo and R. Sabonge, "A competitive analysis of Panama Canal routes," Marit. Policy Manag., vol. 39, no. 6, pp. 555-570, 2012.

[5] L. Tang and S. Jang, "The Evolution from Transportation to Tourism: The Case of the New York Canal System," Tour. Geogr., vol. 12, no. 3, pp. 435-459, 2010.

[6] W. Wang, B. Gheneti, L. A. Mateos, F. Duarte, C. Ratti, and D. Rus, "Roboat: An Autonomous Surface Vehicle for Urban Waterways," in IEEE International Conference on Intelligent Robots and Systems, 2019, pp. 6340-6347.

[7] H. Baroud, K. Barker, J. E. Ramirez-Marquez, and C. M. Rocco S., "Importance measures for inland waterway network resilience," Transp. Res. Part E Logist. Transp.
Rev., vol. 62, pp. 55-67, 2014.

[8] Y. Ii Cao et al., "Inland Vessels Emission Inventory and the emission characteristics of the Beijing-Hangzhou Grand Canal in Jiangsu province," Process Saf. Environ. Prot., vol. 113, pp. 498-506, 2018.

[9] A. A. Fisu, D. Didiharyono, and B. Bakhtiar, "Economic \&amp; Financial Feasibility Analysis of Tarakan Fishery Industrial Estate Masterplan," in IOP Conference Series: Earth and Environmental Science, 2020.

[10] I. Indriatno, R. Irwinsyah, "Aplikasi Analisis Tabulasi Silang (Crosstab) Dalam Perencanaan Wilayah dan Kota," J. Reg. City Plan., vol.9, no. 2, 48-59, 1998.

[11] J. de D. Ortúzar and L. G. Willumsen, Modelling Transport. 2011.

[12] J. Creswell, "Qualitative, quantitative, and mixed methods approaches," in Research design, 2013.

[13] K. F. Punch, Introduction to Social Research: Quantitative and Qualitative Approaches. 2005.

[14] S. Hadi, "Metodologi Research," Univ. Gajah Madha, 2001. 